\title{
Role of computed tomography and mediastinoscopy in the staging of lung cancer: A Canadian opinion poll
}

\author{
Graham L Jones PhD MD, John D Miller MD FRCSC \\ Divisions of Respirology and Critical Care, Department of Medicine and Division of Thoracic \\ Surgery, Department of Surgery, McMaster University, Hamilton, Ontario
}

GL Jones, JD Miller. Role of computed tomography and mediastinoscopy in the staging of lung cancer: $A$ Canadian opinion poll. Can Respir J 1997;4(6):306-310.

OBJECTIVES: To address the Canadian Lung Oncology group's recently published results and recommendations suggesting that mediastinoscopy is unnecessary in the staging nonsmall cell lung cancer when computed tomography shows no enlarged mediastinal lymph nodes (larger than $1 \mathrm{~cm}$ in short axis); to evaluate the practice of thoracic surgeons across Canada in staging presumably operable lung cancer; and to assess the effect of the Canadian Lung Oncology Group's recommendations on current thoracic surgical practice in Canada.

DESIGN: A survey of Canadian thoracic surgeons $(n=38)$ regarding the roles of computed tomography and mediastinoscopy in evaluating mediastinal disease in patients with operable lung cancer.

RESULTS: There was an $89 \%$ response rate. Ninety-one per cent of surgeons used computed tomography routinely, but only $10 \%$ of surgeons thought it to be more accurate than mediastinoscopy. Sixty-eight per cent would rely on a negative scan (nodes smaller than $1 \mathrm{~cm}$ in shortest diameter) to rule out mediastinal disease.

CONCLUSIONS: There are numerous circumstances where negative computed tomography does not adequately assess nodal status. A guideline for the use of computed tomography and mediastinoscopy in evaluating and staging lung cancer is presented. Mediastinoscopy should be considered in the staging of patients with negative computed tomography if the patient is at high risk of mediastinal disease, where negative computed tomography is typically unreliable and when the risk associated with an unnecessary thoracotomy is high.

Key Words: Computed tomography, Guidelines, Lung cancer, Mediastinoscopy, Mediastinum, Staging

\section{Rôle de la tomodensitométrie et de la médiasti- noscopie dans la stadification du cancer du poumon : un sondage d'opinion canadien}

RÉSUMÉ: Rôle de la tomodensitométrie et de la médiastinoscopie dans la stadification du cancer du poumon : un sondage d'opinion canadien

OBJECTIFS : Se pencher sur la récente publication des résultats et des recommandations du Canadian Lung Oncology group qui laissent croire que la médiastinoscopie n'est pas nécessaire dans la stadification du cancer du poumon non à petites cellules quand la tomodensitométrie ne révèle pas d'adénopathie médiastinale (plus grande que $1 \mathrm{~cm}$ dans l'axe court) ; étudier la pratique des chirurgiens thoraciques à travers le Canada en ce qui concerne la stadification du cancer du poumon qu'on estime opérable, et évaluer l'effet des recommandations du Canadian Lung Oncology group sur les pratiques courantes de la chirurgie thoracique au Canada.

voir page suivante 
MODÈLE : Une enquête menée auprès de tous les chirurgiens thoraciques du Canada $(\mathrm{n}=38)$ relativement aux rôles de la tomodensitométrie et de la médiastinoscopie dans l'évaluation d'une atteinte médiastinale chez les patients atteints d'un cancer du poumon opérable.

RÉSULTATS : Le taux de réponse était de $89 \%$. Quatre-vingt onze pour cent des chirurgiens utilisaient systématiquement la tomodensitométrie mais seulement $10 \%$ des chirurgiens pensaient qu'elle était plus précise que la médiastinoscopie. Soixante-huit pour cent feraient confiance à une tomodensitométrie négative (ganglions plus petits que $1 \mathrm{~cm}$ dans l'axe court) pour exclure une atteinte médiastinale.

CONCLUSIONS : Il est fréquent qu'une tomodensitométrie ne soit pas spécifique de l'état ganglionnaire. Une ligne directrice concernant l'utilisation de la tomodensitométrie et de la médiastinoscopie pour évaluer et stadifier le cancer du poumon est présentée. On devrait envisager une médiastinoscopie pour la stadification des patients dont la tomodensitométrie est négative si le patient est à risque élevé pour développer une affection médiastinale, dans les cas où on ne peut généralement pas se fier à une tomodensitométrie négative et quand le risque associé à une thoracotomie inutile est élevé.
$\mathrm{T}$ he Canadian Lung Oncology Group (1) recently assessed the role of computed tomography (CT) scans and mediastinoscopy in the management of nonsmall cell lung cancer (NSCLC) in a well designed prospective randomized trial. Patients were randomised to either a CT or a mediastinoscopy arm. Patients with a 'positive' CT scan (lymph nodes larger than $1 \mathrm{~cm}$ in short axis) had mediastinoscopy. Patients were excluded if the mediastinum was abnormal on chest radiograph or if they had a prior CT scan. The mediastinoscopy group had no CT scan. The impact of CT scan and mediastinoscopy on the primary outcomes of survival and "unnecessary thoracotomy rates" was assessed. An unnecessary thoracotomy was defined as either a thoracotomy for benign disease or thoracotomy without cure (recurrence at three years). There was no difference in the unnecessary thoracotomy rate between the two groups (121 of 342 patients in the mediastinoscopy group had unnecessary thoracotomy compared with 107 of 343 in the CT group). Survival in the two groups was also similar. The sensitivity and specificity of CT scan were reported as $78 \%$ and $69 \%$, respectively. The authors concluded that only a select group of patients require both CT scans and mediastinoscopy. They proposed that mediastinoscopy is unnecessary in staging NSCLC when lymph nodes are less than $1 \mathrm{~cm}$ in length in their short axis on CT scan. On the basis of these results they recommended that "patients with apparently operable lung cancer should all have CT scan of the chest, and those with nodes greater than $1 \mathrm{~cm}$ should undergo mediastinoscopy, whereas the remainder should go directly to thoracotomy".

The purpose of this paper's poll of Canadian thoracic surgeons was to determine current practice regarding the use of CT scan and mediastinoscopy in the preoperative staging of NSCLC. The impact of the Canadian Lung Oncology Group's suggestions on the opinions and practice of surgeons in the evaluation of mediastinal disease in NSCLC was also investigated (1).

\section{PARTICIPANTS AND METHODS}

Thoracic surgeons (surgeons with a major interest in thoracic surgery) in Canada were identified from the Canadian medical directory, the General Thoracic Surgery Club directory and personal knowledge. Each surgeon was sent a simple questionnaire via fax consisting of an introductory paragraph followed by five questions each requiring a yes or no answer (Appendix 1). The questions were designed to gain an appreciation of how each surgeon used CT scans and medi- astinoscopy in the preoperative staging of presumed operable lung cancer.

\section{RESULTS}

Thirty-four of 38 questionnaires were returned (89\% response). One questionnaire was filled out incorrectly. Thirty-three of 34 (97\%) were aware of the study by the Canadian Lung Oncology Group (1). Eleven of 33 (33\%) felt that their practice had changed as a result of this publication. Thirty-one of 33 (91\%) thoracic surgeons used CT routinely as part of their preoperative assessment. Three of $33(9 \%)$ felt that CT scan had replaced mediastinoscopy as a more accurate measure of mediastinal disease. Ninety-one per cent (91\%) felt that mediastinoscopy was more accurate than CT in defining mediastinal disease. Twenty-three of 34 (68\%) used CT scans to rule out mediastinal involvement (no nodes larger than $1 \mathrm{~cm})$.

\section{DISCUSSION}

Our results indicate that although Canadian thoracic surgeons are aware of the Canadian Lung Oncology Group's recommendations, only two-thirds used CT scans to rule out mediastinal disease and fewer still felt that CT was more accurate than mediastinoscopy in defining mediastinal disease.

Accurate staging of the mediastinal lymph nodes is one of the cornerstones in effective management of lung cancer $(2,3)$. CT and mediastinoscopy are currently used to aid in diagnosis and decision-making in the management of operable NSCLC. The usefulness of these procedures remains controversial. Karmy-Jones et al (4) studied 30 patients with presumed unresectable bronchogenic carcinoma on the basis of radiological results alone and who were referred for palliative radiotherapy. The patients all received further surgical staging, which demonstrated that 10 were candidates for resection. Nine of these patients were alive and disease free at a median follow-up of over two years, demonstrating that chest $\mathrm{X}$-ray and CT may not be specific enough to rule out the possibility of surgical cure.

The Canadian Lung Oncology Group (1) has recommended that mediastinoscopy is not required when the CT is negative (nodes smaller than $1 \mathrm{~cm}$ ). This current survey was undertaken to determine the current practices of Canadian thoracic surgeons and to determine whether this recent information had affected their clinical practice. We believe that there are instances when mediastinoscopy is appropriate and 
necessary even if the CT is negative. Evidence-based recommendations for the use of these procedures in practice will be provided where possible.

The addition of mediastinoscopy to the staging of lung cancer in 1965 improved management by more accurately defining inoperable disease (5). Frequently, the presence or absence of mediastinal lymph node disease (N2 or N3 disease) is pivotal in determining appropriate treatment $(6,7)$. Traditionally, patients with N2 or N3 disease are not candidates for curative surgical resection and, therefore, are offered nonsurgical treatment or are entered into experimental neoadjuvant treatment protocols for their disease (2). Patients with nodal metastases at mediastinoscopy have a worse prognosis than those patients with negative mediastinoscopy and resectable positive mediastinal nodes found at thoracotomy (6).

Pearson and associates (7) reported surgical results of patients with mediastinoscopy positive and mediastinoscopy negative NSCLC. When operative mortality, unresected cases and inoperable resections were included in the survival data, the absolute five-year survival for patients with mediastinoscopy positive lymph nodes (N2 disease) was $9 \%$. For patients with a negative mediastinoscopy in whom the N2 disease was identified at thoracotomy (usually in a site inaccessible by mediastinoscopy), a $24 \%$ overall five-year survival was observed. When only patients surviving a complete resection were assessed, the five-year survival was $18 \%$ for those with positive mediastinoscopy and 35\% for those with negative mediastinoscopy. A review by Shields (8) concluded that less than $20 \%$ of patients with $\mathrm{N} 2$ disease are surgical candidates, and the overall survival rate for all patients with $\mathrm{N} 2$ disease is between $3 \%$ and $6 \%$ (8). In recent revisions to the TNM staging of NSCLC $(9,10)$ clear differences have been shown in survival curves between $\mathrm{N} 1$ and N2 disease when defined clinically or surgically.

The results of the Canadian Lung Oncology Group study centre around the outcome measures used, unnecessary thoracotomy and survival. An unnecessary thoracotomy was defined as not only thoracotomy without resection but also a thoracotomy for benign disease (a comment on failed bronchoscopy or failed needle biopsy more than mediastinoscopy) and thoracotomy with clinical recurrence within three years (a comment on other preoperative staging techniques as much as mediastinoscopy). The authors anticipate mediastinoscopy (a staging tool) might affect the overall survival of lung cancer. Survival end-points appropriately assess the effects of treatment but cannot assess staging protocols.

We are concerned that the recommendation made by the Canadian Lung Oncology Group fails to account for the subsets of patients for whom mediastinoscopy is warranted, even if lymph nodes are less than $1 \mathrm{~cm}$ on CT scan, specifically patients with adenocarcinoma, patients entering clinical trials, patients with resectable T3 tumours, patients with left upper lobe tumours, and patients with synchronous lung primary and solitary brain metastasis being considered for resection.
The approach to the staging of lung cancer in the late 1980s has been evaluated in the United Kingdom (11) and the United States (12). In the British study, $40 \%$ of surgeons did not stage mediastinal disease either by CT scan or mediastinoscopy, resulting in an unacceptably high rate of unnecessary thoracotomies. A similar proportion of British surgeons did not sample mediastinal lymph nodes at thoracotomy, which was felt to lead to "under staging". In the United States, a national survey of lung cancer care reviewed the treatment of 34,000 people with lung cancer and indicated that approximately $6 \%$ of all patients had thoracotomy without resection (unnecessary thoracotomy) and 17\% had mediastinoscopy - some with enlarged nodes on CT (62\%) and others not (38\%). In the patients who had positive results on mediastinoscopy, 27\% had normal nodes on CT (12) (false negatives).

Izbicki et al (13) prospectively compared the accuracy of $\mathrm{CT}$ and surgical assessment for $\mathrm{T}$ and $\mathrm{N}$ staging of bronchial carcinoma to the final pathology report. The stage of the primary tumour (T stage) was correctly determined by CT and bronchoscopy in $85 \%$ of cases. Surgical assessment correctly determined the $\mathrm{T}$ stage in $92 \%$ compared with the final pathological analysis. On the other hand, CT scan did not accurately predict mediastinal lymph node involvement, having a sensitivity of $29 \%$ and a specificity of $93 \%$. When the lymph nodes were grouped according to size criteria, there was a $14 \%$ rate of metastatic involment in nodes smaller than $1 \mathrm{~cm}$ on CT scan, and $71 \%$ of nodes larger than $1 \mathrm{~cm}$ were normal. When CT is used to identify disease in specific nodal stations as defined by the American Thoracic Society (ATS) (14), sensitivities of $44 \%$ (15) and 66\% (16) have been reported. Furthermore, in CT scans rated positive by size criteria and by mediastinoscopy, tumour was found not in enlarged nodes but in normal-sized nodes from another nodal station (16). In another series $37 \%$ of lymph nodes that measured 2 to $4 \mathrm{~cm}$ in the short axis were hyperplastic and contained no metastases (15).

Two studies have measured interobserver reliability in describing mediastinal lymph nodes on CT scan. Observer agreement was described as poor to good (17). There was poor agreement between observers with lymph nodes in the left superior mediastinum. The authors concluded that "the disagreement was sufficient that it likely contributes to suboptimal sensitivity and specificity of CT in detecting tumor spread". A study comparing CT scans with mediastinoscopy and thoracotomy findings found large interobserver variability and low sensitivities (40\% to 69\%), indicating that negative mediastinal lymph nodes do not eliminate the need for mediastinoscopy or exploration of the mediastinum at the time of operation (18).

A prospective study comparing magnetic resonance imaging, CT and mediastinoscopy in bronchogenic carcinoma found CT scan to be frequently misleading in preoperative assessment of mediastinal nodes. These authors found CT scans to have a specificity of $88.7 \%$ and a sensitivity of only $71 \%$ (19).

Mediastinoscopy remains the most accurate prethora- 
cotomy method of assessing N2 and N3 disease (2,20-22). Metastatic disease in small nodes on a CT scan (nodes smaller than $1 \mathrm{~cm}$ ) occurs especially in patients with adenocarcinoma (23). Mediastinoscopy may provide the only histological proof of small cell lung cancer and thereby prevent unnecessary thoracotomy. The routine use of preoperative mediastinoscopy has resulted in a resectability rate at thoracotomy of $93 \%$ (5).

In experienced hands, cervical mediastinoscopy is safe $(24,25)$ and can be performed on an out-patient basis (26). Mediastinal lymph node location has been defined for the purpose of staging by the ATS (14) with recent modifications by the American Joint Comittee on Cancer (9). Mediastinoscopy permits direct visualization and sampling of the paratracheal ATS node station (2 R/L, 4 R/L), trachealbronchial (10 R) and anterior subcarinal lymph node (station 7). Anterior mediastinoscopy and extended cervical mediastinoscopy expands the assessment to include the aorta pulmonary window and anterior mediastinal nodes (ATS stations 5 and 6 , nodes anterior to the great vessels).

\section{SUMMARY AND RECOMMENDATIONS}

In general, a CT scan of the mediastinum appears useful, with comparable results at less cost than mediastinoscopy, when ruling out mediastinal disease in patients undergoing treatment for lung cancer. There are, however, specific circumstances where the presence of small nodes on CT scan does not rule out metastatic disease, and the sensitivity of a CT scan remains the issue when ruling in disease. The best performance is achieved (when ruling in disease) if both size criteria and clinical circumstances are combined, reaching a sensitivity for CT scan of 0.85 . To effect a positive outcome in life expectancy, comparing invasive and noninvasive staging strategies, specificity must exceed 0.90. This currently is not possible.

Mediastinoscopy has a sensitivity of 0.87 with a specificity of 1.0. Its accuracy is 0.95 . For patients whose mediastinum is positive on a CT scan and in whom the histology (of these nodes) would affect treatment decisions, mediastinoscopy remains the 'gold standard' and is recommended.

When the chest CT scan is negative (nodes smaller than $1 \mathrm{~cm}$ ) mediastinoscopy can generally be eliminated from the preoperative work-up without affecting survival and unnecessary thoracotomy rates with the following exceptions.

- Mediastinoscopy should be considered in circumstances when small nodes are more likely to contain malignancy (when the tumour is known to be adenocarcinoma; M1 disease if the only known metastasis is a solitary brain metastasis being considered for resection).

- Mediastinoscopy should be considered if the patient will be enrolled in a trial of adjuvant therapy postresection.

- Mediastinoscopy should be considered when the presence or absence of nodal disease will have an extraordinary effect on the risk-benefit ratio in T3 disease.
Sampling of mediastinal nodes at resection is also recommended in those with negative mediastinoscopy. Accurate staging of NSCLC must include mediastinal lymph node sampling intraoperatively when appropriate.

\section{CONCLUSIONS}

A recent report by the Canadian Lung Oncology Group suggests the mediastinoscopy should not be used in patients with a negative CT scan (mediastinal lymph nodes less than $1 \mathrm{~cm})$. The present opinion poll of Canadian thoracic surgeons has shown that personal opinions and practices are varied. An overwhelming majority of surgeons does not think that CT scan alone is sufficient to assess accurately mediastinal lymph node involvement. However, two-thirds of Canadian surgeons use CT in isolation to rule out mediastinal disease. The literature supports our belief that the optimum preoperative assessment of mediastinal lymph node status is unclear, but that CT scan and mediastinoscopy have independent and complementary roles in clinical decision-making in both diagnosis and treatment. We recommend that mediastinoscopy be considered in the prethoracotomy staging of patients at high risk of mediastinal disease, where CT is hardest to interpret and when the risks associated with an unnecessary thoracotomy are high.

\section{REFERENCES}

1. The Canadian Lung Oncology Group. Investigation for mediastinal disease in patients with apparently operable lung cancer. Ann Thorac Surg 1995;60:1382-9.

2. Miller JD, Gorenstein LA, Patterson GA. Staging: the key to rational management of lung cancer. Ann Thorac Surg 1992;53:170-8.

3. Pearson FG. Staging of the mediastinum; role of mediastinoscopy and computed tomography. Chest 1993;103:346S-8S

4. Karmy-Jones R, Vallieres E, Lewis JW, Dundas G. Investigation of patients with apparently inoperable lung cancer. Can Respir J 1996;3:309-13.

5. Luke WP, Pearson FG, Todd TRJ, Patterson GA, Cooper JD. Prospective evaluation of mediastinoscopy for the assessment of carcinoma of the lung. J Thorac Cardiovasc Surg 1986;91:53-6.

6. vanKlaveran RJ, Festen J, Otten HJAM, Cox AL, deGraaf R, Lacquet LK. Prognosis of unsuspected but completely resectable N2 non-small cell lung cancer. Ann Thorac Surg 1993;56:300-4.

7. Pearson FG, Delarue NC, Ilves R, Todd TRJ, Cooper JD. Significance of positive superior mediastinal nodes identified at mediastinoscopy in the patients with resectable cancer of the lung. J Thorac Cardiovasc Surg 1982;83:1-11.

8. Shields TW. Significance of ipsilateral mediastinal lymph node metastasis (N2 disease) in non-small cell carcinoma of the lung. J Thorac Cardiovasc Surg 1990;99:48-53.

9. Mountain CF, Dresler CM. Regional lymph node classification for lung cancer staging. Chest 1997;111:1718-1723. (Abst)

10. Mountain CF. Revisions in the international system for staging lung cancer. Chest 1997;111:1710-7.

11. Tsang GMK, Watson DCT. The practice of cardiothoracic surgeons in the perioperative staging of non-small cell lung cancer. Thorax 1992;47:3-5

12. Humphrey EW, Smart CR, Winchester DP, et al. National survey of the pattern of care for carcinoma of the lung. J Thorac Cardiovasc Surg 1990;100:837-43.

13. Izbicki JR, Thetter O, Karg O, et al. Accuracy of computed tomographic scan and surgical assessment for staging of bronchial carcinoma, a prospective study. J Thorac Cardiovasc Surg 1992;104:413-20.

14. Tisi GM, Friedman PJ, Peters RM, et al. Clinical staging of primary lung cancer. Am Rev Respir Dis 1983;127:659-64.

15. McCloud TC, Bourgouin PM, Greenberg RW, et al. Bronchogenic 


\section{Re: Assessing the mediastinum in potentially operable NSCLC.}

We are conducting an opinion poll to examine the role of mediastinoscopy and CT scan of the mediastinum in the staging of lung cancer across Canada.

A recent report in the Annals of Thoracic Surgery authored by the Canadian Lung Oncology Group (Ann Thoracic Surg 60: 1382-9; 95) concludes "patients with apparently operable lung cancer should all have CT scan of the chest and those with nodes $>1 \mathrm{~cm}$ should undergo mediastinoscopy, wheras the remainder can proceed directly to thoracotomy." In other words: remainder can proceed directly to thoracotomy. "In other words; mediastinoscopy is not needed in the preoperative staging of limited non
small cell lung cancer when the CT scan shows no evidence of mediastinal disease (nodes $<1 \mathrm{~cm}$ ).

Do you use CT scan routinely ? yes no

Are you aware of the publication refered to above ?

Has your practice changed as a result of this publication ?

Has CT scan of the mediastinum replaced mediastinoscopy as a more accurate measure of mediastinal disease for patients undergoing treatment for a lung cancer ?

In general; Do you use CT scan to rule out significant mediastinal involvement? If yes are there exceptions to your practice? (list below, When do you do mediastinoscopy if nodes are $<1 \mathrm{~cm}$ ?)

yes no

yes no

yes no

yes no

Thankyou for your time in responding to these questions.

Appendix 1) Survey/Questionnaire faxed to Canadian thoracic surgeons. CT Computed tomography; NSCLC Nonsmall cell lung cancer

carcinoma: analysis of staging in the mediastinum with CT by correlative lymph node mapping and sampling. Radiology 1992;182:319-23.
16. Staples CA, Muller NL, Miller RR, Evans KG, Nelems B. Mediastinal nodes in bronchogenic carcinoma: comparison between CT and mediastinoscopy. Radiology 1988;167:367-72.

17. Guyatt GH, Lefcoe M, Walter S, et al. Interobserver variation in the computed tomographic evaluation of mediastinal lymph node size in patients with potentially resectable lung cancer. Chest 1995;107:116-9.

18. Bollen ECM, Goei R, Hof-Grootenboer BE, Versteege CWM, Engelshove HA, Lamers RJS. Interobserver variability and accuracy of computed tomographic assessment of nodal status in lung cancer. Ann Thorac Surg 1994;58:158-62.

19. Patterson GA, Ginsberg RJ, Poon RY. A prospective evaluation of magnetic resonance imaging, computed tomography and mediastinoscopy in the preoperative assessment of mediastinal node status in bronchogenic carcinoma. J Thorac Cardiovasc Surg 1987;94:679-84

20. Pearson FG. An evaluation of mediastinoscopy in the management of presumably operable bronchial carcinoma. J Thorac Cardiovasc Surg 1968;55:617-25.

21. Pearson FG, Nelems JM, Henderson RD, Delarue NC. The role of mediastinoscopy in the selection of treatment for bronchial carcinoma with involvement of superior mediastinal lymph nodes. J Thorac Cardiovase Surg 1972;64:383-90.

22. van Schil PE, van Hee RH, Schoofs EL. The value of mediastinoscopy in preoperative staging of lung cancer. J Thorac Cardiovasc Surg 1989;40:240-4.

23. Vallieres E, Walters PF. Incidence of mediastinal node involvement in clinical T1 bronchogenic carcinomas. Can J Surg 1987;30:3431-2.

24. Cooper JD, Ginsberg RJ. Mediastinoscopy in the preoperative evaluation of patients with bronchogenic carcinoma. In: Kittle CF, ed. Current Controversies in Thoracic Surgery. Philadelphia: WB Saunders Co, 1986;1:162-8. (Abst)

25. Coughlin M, Deslauriers J, Beaulieu M, et al. Role of mediastinoscopy in pretreatment staging of patients with primary lung cancer. Ann Thorac Surg 1985;40:556-60.

26. Cybulsky IJ, Bennett WF. Mediastinoscopy as a routine outpatient procedure. Ann Thorac Surg 1994;58:176-8. 


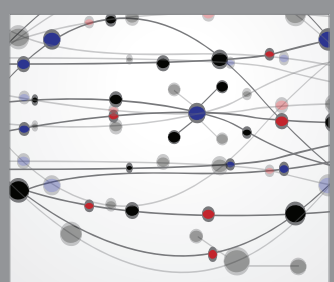

The Scientific World Journal
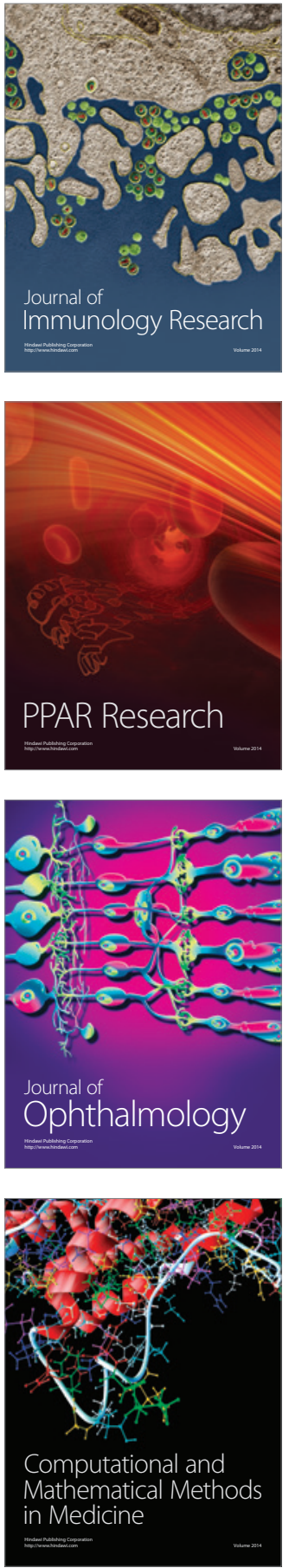

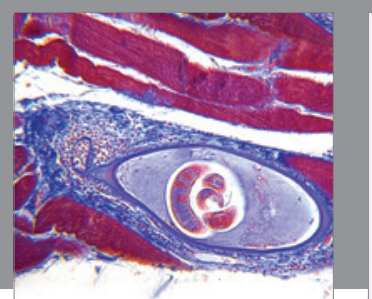

Gastroenterology Research and Practice

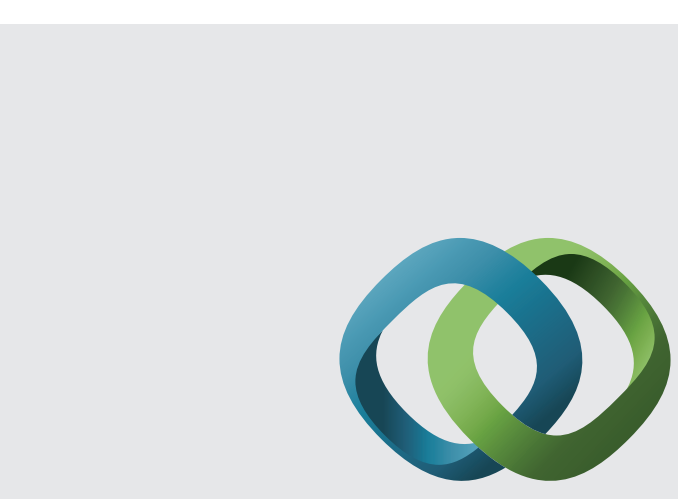

\section{Hindawi}

Submit your manuscripts at

http://www.hindawi.com
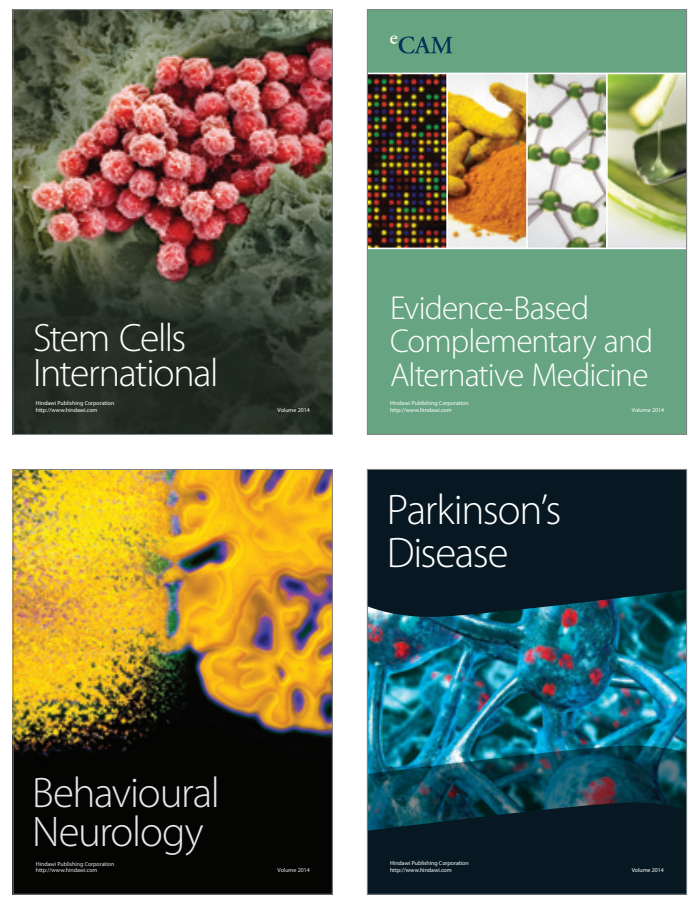
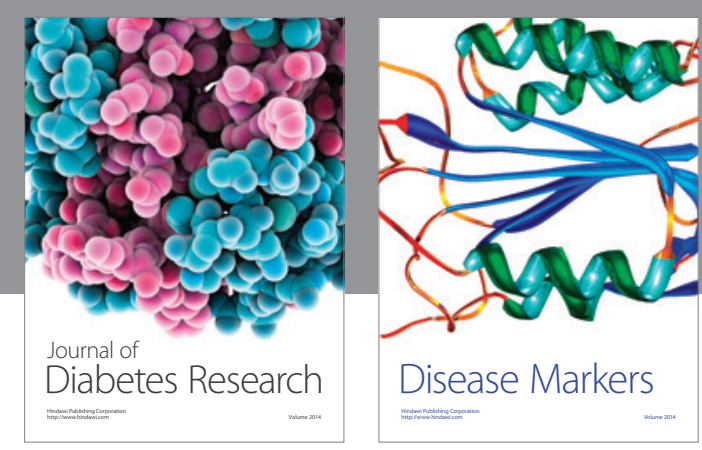

Disease Markers
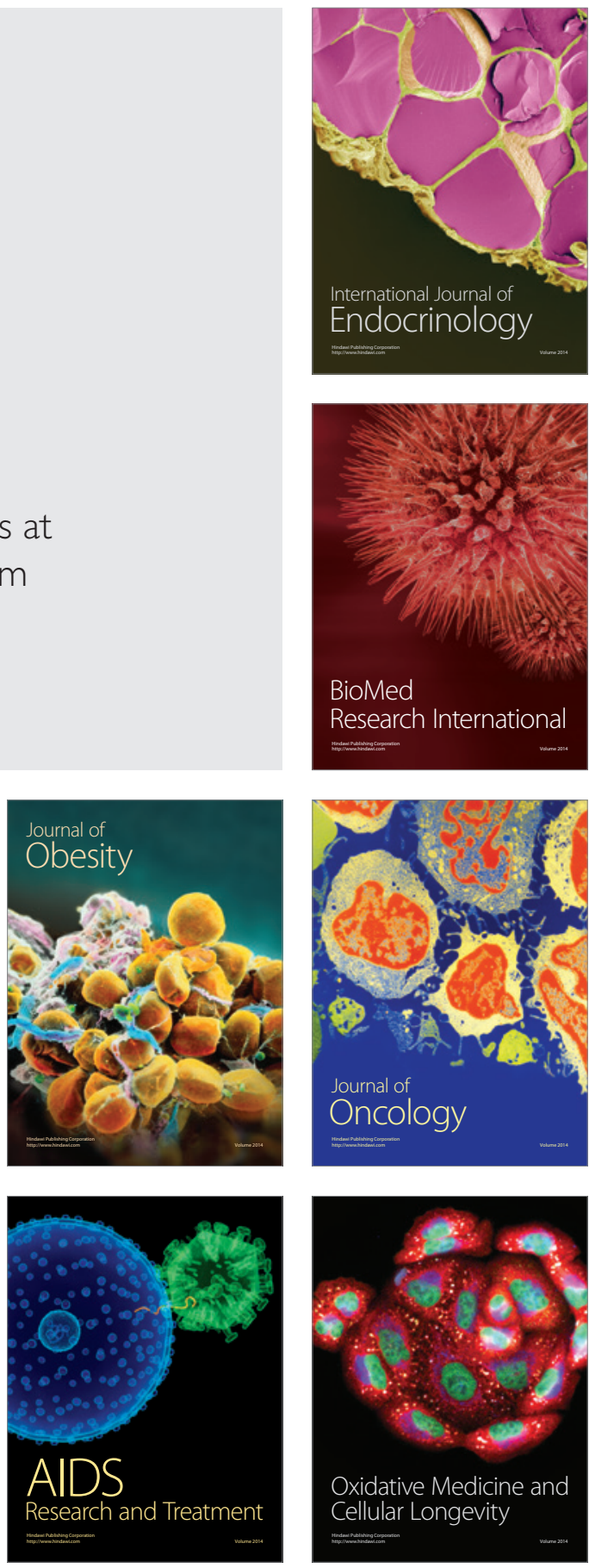